\title{
Nanoscale
}

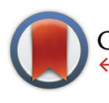

CrossMark

Cite this: Nanoscale, 2014, 6, 13586

\section{Tungsten oxide nanorod growth by pulsed laser deposition: influence of substrate and process conditions}

\author{
Peng Huang, $\dagger^{\mathrm{a}}$ M. Mazhar Ali Kalyar, $\dagger^{\mathrm{a}}$ Richard F. Webster, ${ }^{\mathrm{b}}$ David Cherns ${ }^{\mathrm{b}}$ and \\ Michael N. R. Ashfold*a
}

\begin{abstract}
Tungsten oxide nanorods (NRs) have been grown on W, Ta and Cu substrates following 193 nm pulsed laser ablation of a $\mathrm{WO}_{3}$ target in a low background pressure of oxygen. The deposited materials were analysed by scanning and (high resolution) transmission electron microscopy (HRTEM), selected area electron diffraction (SAED), X-ray diffraction, Raman and X-ray photoemission spectroscopy, and tested for field emission. In each case, HRTEM analysis shows NR growth along the [100] direction, and clear stacking faults running along this direction (which are also revealed by streaking in the SAED pattern perpendicular to the growth axis). The NR composition in each case is thus determined as sub-stoichiometric $\mathrm{WO}_{3-\delta}$, but the NR morphologies are very different. NRs grown on W or Ta are short (hundreds of nm in length) and have a uniform cross-section, whereas those grown on a $\mathrm{Cu}$ substrate are typically an order of magnitude larger, tapered, and display a branched, dendritic microstructure. Only these latter NRs give significant field emission
\end{abstract}

Received 15th July 2014 Accepted 13th September 2014 DOI: $10.1039 / \mathrm{c} 4 \mathrm{nr} 03977 \mathrm{~g}$ www.rsc.org/nanoscale

\section{Introduction}

Tungsten oxide $\left(\mathrm{WO}_{x}, x \leq 3\right)$, an n-type semiconducting metal oxide with band gap $E_{\mathrm{g}} \sim 2.6-3.0 \mathrm{eV}$, attracts interest by virtue of its rich crystallography, its many attractive properties and the diversity of routes by which it can be prepared in lowdimensional nanostructured form. ${ }^{1}$ Chromism (i.e. colour change in response to external stimuli such as voltage, reducing gases, heat and/or light) ${ }^{2,3}$ is arguably its most distinctive property, with real or potential applications in smart windows, flat panel displays, optical memory and read-write-erase devices, but other reported applications of tungsten oxide films include photocatalysis, ${ }^{4}$ water splitting, ${ }^{5}$ gas sensing applications $^{6,7}$ and dye sensitized solar cells. ${ }^{8}$

$\mathrm{WO}_{x}$ structures are typically based on slightly distorted variants of the $\mathrm{ReO}_{3}$ cubic crystal structure, with each metal atom lying at the centre of an octahedron of $\mathrm{O}$ atoms. Tunnels of varying shapes and sizes may thus arise. Stoichiometric $\mathrm{WO}_{3}$

\footnotetext{
${ }^{a}$ School of Chemistry, University of Bristol, Bristol, BS8 1TS, UK. E-mail: mike.ashfold@bris.ac.uk; Tel: +44 (o)1179288312

${ }^{b}$ School of Physics, University of Bristol, Tyndall Avenue, Bristol, BS8 1TL, UK $\dagger$ Permanent address: Department of Physics, Lanzhou University, Lanzhou 730000 , China.

$\$$ Permanent address: Department of Physics, University of Sargodha, Sargodha, Pakistan.
}

itself can exist in several different polymorphs formed by appropriate tilting and/or rotation of the constituent $\mathrm{WO}_{6}$ octahedra without relaxing the requirement of corner sharing. As with other perovskite-based transition metal oxides, however, tungsten oxide also readily tolerates oxygen vacancies, which can coalesce to form defects (shear planes). Such $\mathrm{WO}_{x}(x \leq 3)$ structures necessarily consist of both edge- and corner-shared octahedra, and many stable sub-stoichiometric structures have been characterised. ${ }^{1,9}$

Relative to the bulk material, nanostructured $\mathrm{WO}_{x}$ samples will display an increased surface-to-volume ratio and may thus be expected to offer enhanced performance with respect to properties that are sensitive to, for example, modifications to the surface energies or possible quantum confinement effects. ${ }^{1}$ The detailed properties of low-dimensional materials are sensitive to many factors, however, including chemical composition, thermochemical (phase) stability, crystal structure, surface morphology, porosity, etc., so the exploration of different routes to forming nanostructured $\mathrm{WO}_{x}$ remains a very active area of research. Demonstrated growth methods include both solution-based (hydrothermal methods, acid-bath, solgel, electrodeposition, etc. $)^{1,10-14}$ and vapour phase approaches (e.g. physical vapour deposition, thermal evaporation, sputtering, etc.), ${ }^{1,15,16}$ with post-annealing in oxygen or air offering further possibilities for tuning the $\mathrm{O}$ content, phase, and crystallinity of the as-grown material. 
Pulsed laser deposition (PLD) has also been used to produce $\mathrm{WO}_{x}$ films, ${ }^{17-23}$ including films composed of nanorods (NRs) on quartz substrates. ${ }^{24,25}$ PLD offers the advantage of relatively slow growth, in a clean and dry environment. In the case of $\mathrm{ZnO}$, for example, PLD constitutes a catalyst-free route to forming arrays of high quality, aligned NRs, with controllable diameter and aspect ratio. ${ }^{26,27}$ Here, we show that PLD also offers a route to forming $\mathrm{WO}_{x} \mathrm{NRs}$ on a range of metal substrates (tungsten, tantalum and copper), and explore the sensitivity of the deposition process to conditions like substrate temperature, $\mathrm{O}_{2}$ pressure, and incident fluence. The present study confirms that $\mathrm{WO}_{x}$ NRs can be grown on each of these substrates with just subtle changes in process conditions, but also reveals that the crystallinity and morphology of the resulting NRs is sensitively dependent on process conditions (particularly the choice of substrate).

\section{Experimental}

$\mathrm{WO}_{x}$ NRs were deposited on $\mathrm{W}$ (Goodfellow, as rolled, 99.95\% purity), Ta (Testbourne, rolled bright annealed, 99.99\% purity) and $\mathrm{Cu}$ (Goodfellow, annealed, 99.9\% purity) foil substrates using apparatus that has been described previously. ${ }^{26}$ The deposition chamber was evacuated using a rotary-backed turbomolecular pump, yielding a typical base pressure of $\sim 1 \times$ $10^{-6}$ Torr. The output of an ArF excimer laser (Coherent, COMPex Pro 102, $193 \mathrm{~nm}, 10 \mathrm{~Hz}$ repetition rate) was focused onto a rotating $\mathrm{WO}_{3}$ target (Testbourne, hot pressed polycrystalline sample, $99.95 \%$ purity) at a $45^{\circ}$ incident angle, yielding an incident fluence $F=6-10 \mathrm{~J} \mathrm{~cm}^{-2}$. The resulting plume of ablated material propagates roughly symmetrically about the target surface normal and impinges on the substrate, which is positioned at a distance $D=70 \mathrm{~mm}$ from the target. Substrates were ultrasonically cleaned in acetone, then washed with 99.98\% ethanol, dried in air, and attached to a $250 \mathrm{~W}$ tungsten halogen quartz bulb (used as a heater, and capable of maintaining the substrate temperature, $T_{\text {sub }}$, within $10^{\circ} \mathrm{C}$ of any selected value in the range $25 \leq T_{\text {sub }} \leq 700{ }^{\circ} \mathrm{C}$ ) for the duration of the deposition, $t$. The chamber is designed to allow backfilling with a steady $(10 \mathrm{sccm})$ flow of oxygen, hence providing for a background pressure in the range $0 \leq p \mathrm{O}_{2} \leq 100 \mathrm{~m}$ Torr during the PLD stage. 'Base' conditions were taken to correspond to $p \mathrm{O}_{2}=10 \mathrm{mTorr}$.

The as-grown $\mathrm{WO}_{x}$ samples were characterized by field emission scanning electron microscopy (FE-SEM, JEOL6300LV), transmission electron microscopy (TEM, JEOL 1200EX), high resolution transmission electron microscopy (HRTEM, JEOL 2010), selected area electron diffraction (SAED, Philips EM430 TEM), X-ray diffraction (XRD, Bruker AXS D8 Advance powder diffractometer with $\mathrm{Cu}$ Ko radiation), Raman spectroscopy (Renishaw InVia spectrometer, $632.8 \mathrm{~nm}$ excitation), X-ray photoemission spectroscopy (XPS, Kratos Axis Ultra DLD photoelectron spectrometer with a monochromatic Al Ko source (1486.6 eV)), and their field emission properties investigated.

\section{Results and discussion}

Observations and analyses of $\mathrm{WO}_{x} \mathrm{NR}$ samples grown on $\mathrm{W}$, Ta and $\mathrm{Cu}$ substrates are presented and discussed in sequence. Experimental parameters $\left(F, T_{\text {sub }}, t\right.$ and $\left.p \mathrm{O}_{2}\right)$ were varied in each case, but with particular emphasis on identifying process conditions that led to the richest nanostructure rather than seeking to maintain constancy across the three families of depositions. The various substrates were cleaned, successively, in acetone then ethanol in an ultrasonic bath, then dried with compressed air, but otherwise used as supplied. Only reflections attributable to the bare metal were identifiable by XRD, but we recognize that each substrate must be covered with a thin surface oxide layer from the very start of the PLD process.

\subsection{Growth on $\mathrm{W}$ substrates}

Heating a W substrate ${ }^{28}$ (or a W film on a Si substrate ${ }^{29}$ ) in an oxygen-containing atmosphere is a known route to forming $\mathrm{WO}_{x}$ NRs. Environmental TEM studies of $\mathrm{WO}_{x} \mathrm{NR}$ growth from a W wire maintained at $T_{\text {sub }}=800{ }^{\circ} \mathrm{C}$ in a low pressure of $\mathrm{O}_{2}$ have led to the suggestion that growth is initiated by thermally induced cracking of the natural $\mathrm{WO}_{x}$ surface layer, formation of tungsten protrusions by diffusion through these cracks, and subsequent oxidation. ${ }^{28}$ The SEM images shown in Fig. 1 allow
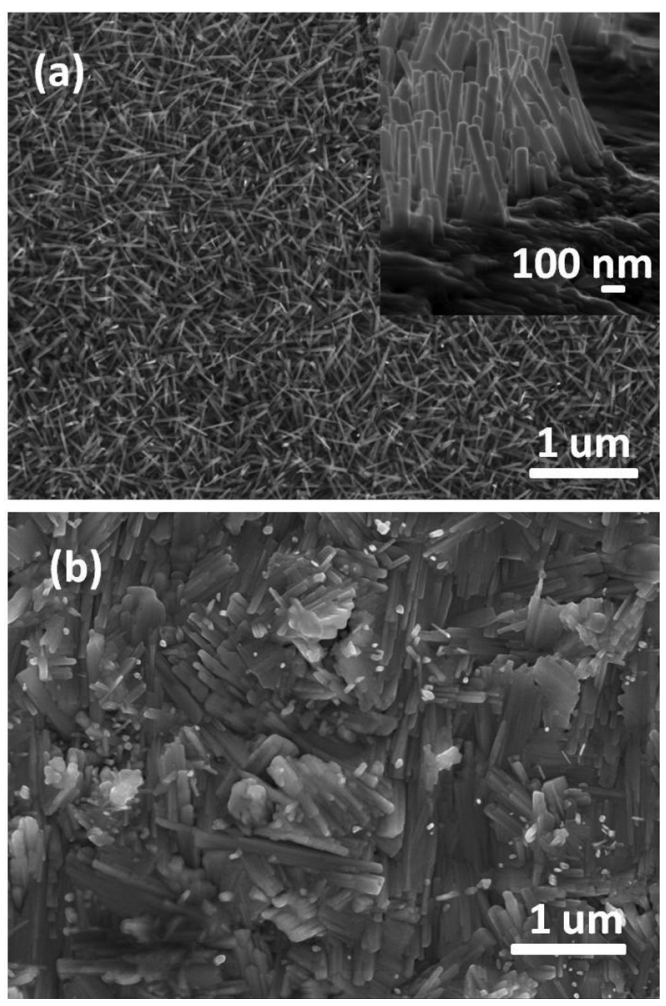

Fig. 1 SEM images of a $W O_{x}$ layer grown on a $\mathrm{W}$ substrate at $T_{\text {sub }}=$ $700{ }^{\circ} \mathrm{C}$ in the presence of $\mathrm{OO}_{2}=10 \mathrm{mTorr}$ for $t=45 \mathrm{~min}$ (a) with and (b) without the contribution from $193 \mathrm{~nm}$ ablation of the $\mathrm{WO}_{3}$ target at $F=$ $10 \mathrm{~J} \mathrm{~cm}^{-2}$. The inset in (a) shows a section (tilt view) through the PLDassisted NR array obtained after cleaving the sample. 
comparison of two $\mathrm{WO}_{x} \mathrm{NR}$ samples grown on a $\mathrm{W}$ substrate under conditions that were identical $\left(T_{\text {sub }}=700{ }^{\circ} \mathrm{C}, p \mathrm{O}_{2}=\right.$ $10 \mathrm{mTorr}, t=45 \mathrm{~min}$ ) in all details bar one: sample (a) was grown with and sample (b) without the PLD contribution (i.e. the latter was produced by thermal oxidation only). The PLDfree sample (Fig. 1(b)) shows vestigial surface nodules and some coarse rod-like structures, but the with-PLD sample shows a dense covering of imperfectly aligned NRs, the details of which depend sensitively on the deposition conditions. As Fig. 2 shows, the NR coverage and the NR lengths in the withPLD samples both increase greatly as $T_{\text {sub }}$ is increased from $500{ }^{\circ} \mathrm{C}$ to $700{ }^{\circ} \mathrm{C}$. Increasing $p \mathrm{O}_{2}$ from 10 to 100 mTorr (at $T_{\text {sub }}$ $=700^{\circ} \mathrm{C}$ ) results in shorter, thicker NRs.
Fig. 3(a) shows XRD spectra of the with-PLD $\mathrm{WO}_{x}$-on-W sample shown in Fig. 1(a) and a sample from the polycrystalline target (scraped onto a Si support). The three peaks at $2 \theta \sim$ $23-24.5^{\circ}$ in the spectrum of the target material confirms its predominantly monoclinic nature (JCPDS no. 43-1035), whereas the XRD spectrum of the with-PLD (and the PLD-free) samples are dominated by the (200) and (400) reflections of cubic- $\mathrm{WO}_{3}$ (JCPDS no. 46-1096, labelled according to a $7.6 \AA$ unit cell) and the $\mathrm{W}$ substrate itself. The dominance of these reflections implies preferential (100) alignment, that we assume to be directed by the oxidizing substrate. Fig. 3(b) and (c) illustrate the effects of, respectively, increasing $T_{\text {sub }}$ (at constant $p \mathrm{O}_{2}=10 \mathrm{~m}$ Torr) and increasing $p \mathrm{O}_{2}$ (at constant $T_{\mathrm{sub}}=$
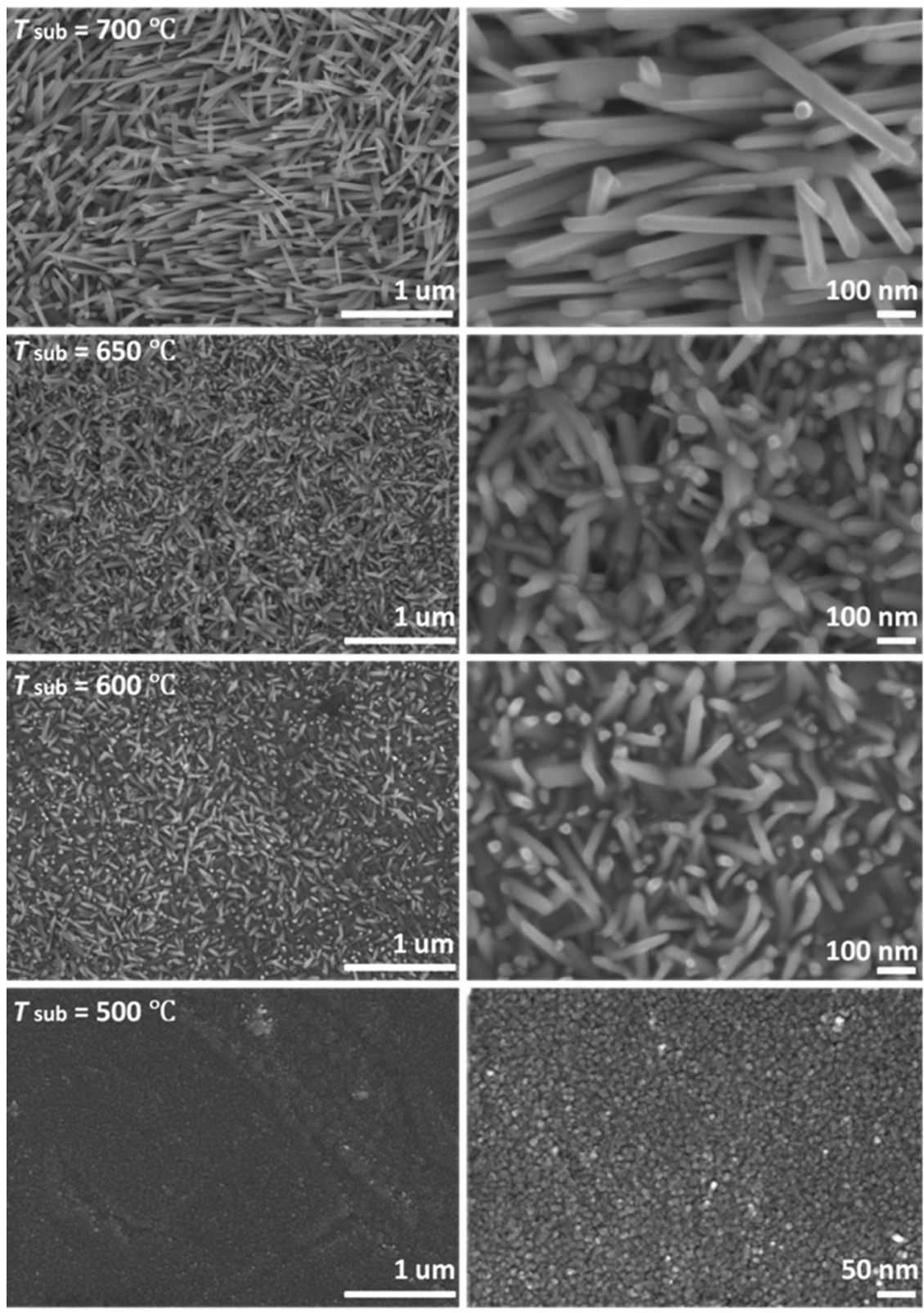

Fig. 2 Low and high resolution SEM images (left and right hand columns, respectively) illustrating the $T_{\text {sub }}$ dependence of the morphology of the $W_{x}$ layer formed on a W substrate by $193 \mathrm{~nm}$ ablation of the $\mathrm{WO}_{3}$ target at $F=10 \mathrm{~J} \mathrm{~cm}^{-2}$ in $p \mathrm{O}_{2}=10 \mathrm{mTorr}$ for $t=45 \mathrm{~min}$. 

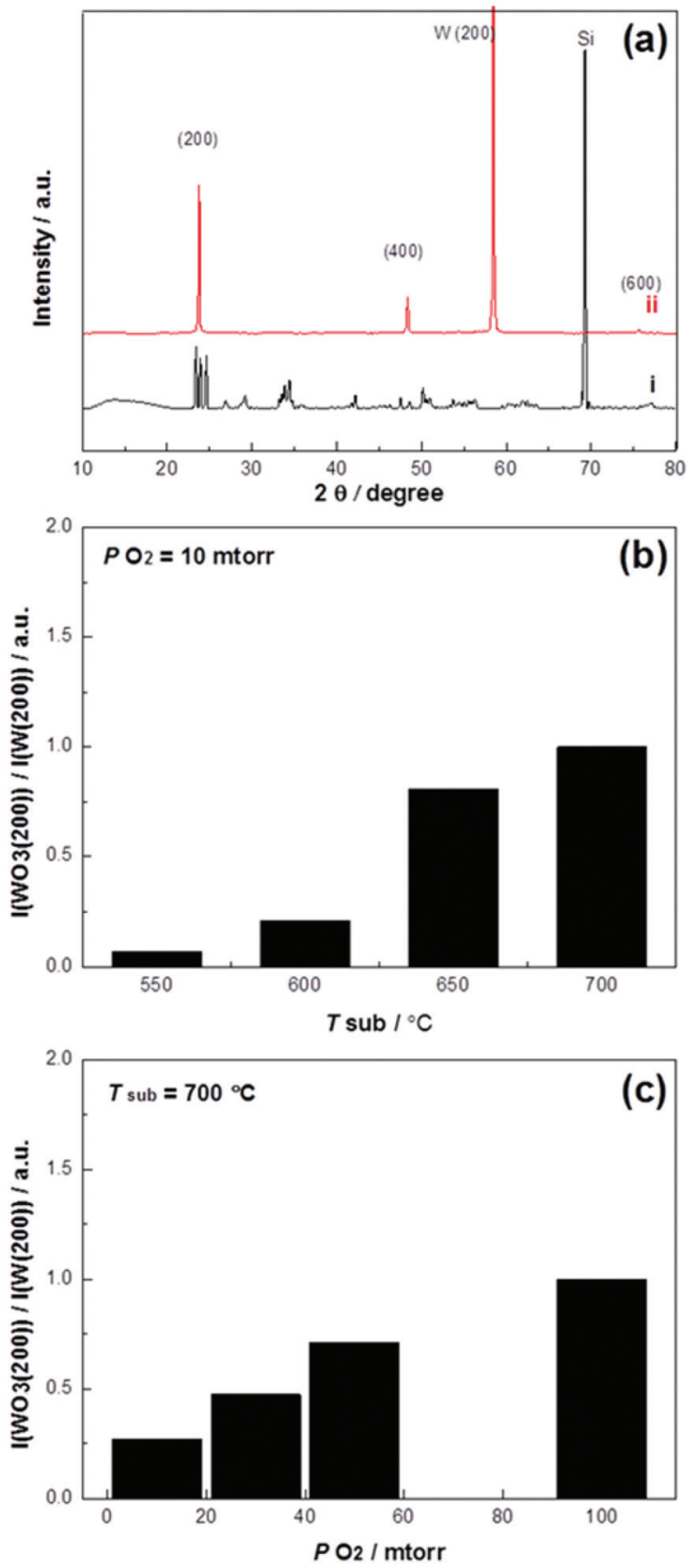

Fig. 3 (a) XRD spectra of (i) material scraped from the $\mathrm{WO}_{3}$ target onto a Si substrate (that confirms the (predominantly) monoclinic structure of the target material) and (ii) the $\mathrm{WO}_{x}$ layer formed on a W substrate maintained at $T_{\text {sub }}=700{ }^{\circ} \mathrm{C}$ by $193 \mathrm{~nm}$ ablation of the $\mathrm{WO}_{3}$ target at $F=10 \mathrm{~J}$ $\mathrm{cm}^{-2}$ in the presence of $\mathrm{pO}_{2}=10 \mathrm{mTorr}$ for $t=45 \mathrm{~min}$ (the dominant peaks in which are attributable to (100) aligned cubic- $\mathrm{WO}_{3}$ (as well as peaks from the underlying $W$ substrate)). The lower panels show the way the relative intensities of the (200) reflections of $\mathrm{WO}_{3}$ and $\mathrm{W}$ in XRD spectra of PLD-grown samples vary with (b) $T_{\text {sub }}$ (at $\mathrm{pO}_{2}=10 \mathrm{mTorr}$ ) and (c) $\mathrm{pO}_{2}$ (at $T_{\text {sub }}=700^{\circ} \mathrm{C}$ ). The ratios in (b) and (c) have been scaled such that the largest ratio in each case is 1.0 .

$700{ }^{\circ} \mathrm{C}$ ) as evidenced by the relative intensities of the (200) reflections of $\mathrm{WO}_{3}$ and $\mathrm{W}$ (at $2 \theta=23.6$ and $58.3^{\circ}$, respectively) - with the largest ratio in each plot arbitrarily scaled to 1.0. Clearly, increasing $T_{\text {sub }}$ and $p \mathrm{O}_{2}$ both have the effect of increas-
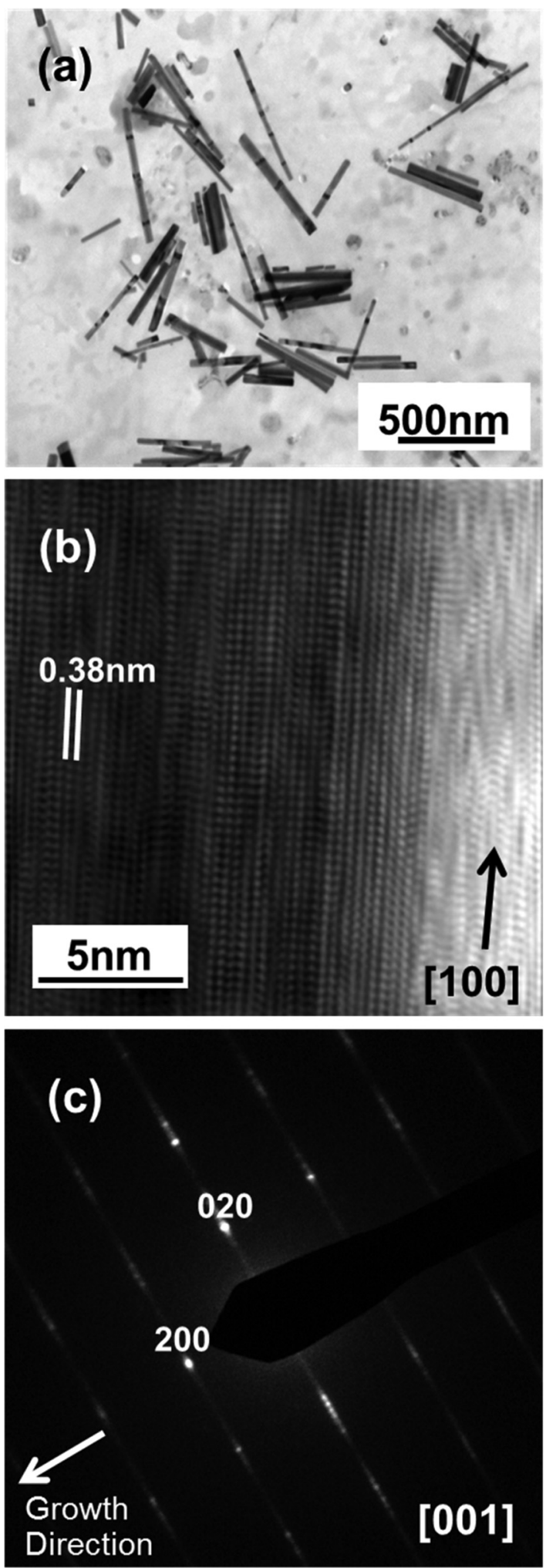

Fig. 4 (a) Low resolution TEM image of material broken from the $W_{x}$ layer grown on a W substrate at $T_{\text {sub }}=700{ }^{\circ} \mathrm{C}$ in the presence of $\mathrm{pO}_{2}=$ $10 \mathrm{mTorr}$ for $t=45 \mathrm{~min}$ with the contribution from $193 \mathrm{~nm}$ ablation of the $W_{3}$ target at $F=10 \mathrm{~J} \mathrm{~cm}^{-2}$. (b) HRTEM image of the tip of a single NR, showing the $d=0.38 \mathrm{~nm}$ fringe spacing and an obvious stacking fault. (c) SAED pattern taken from this NR sample, indexed as cubic$\mathrm{WO}_{3}$. 
ing the relative intensity of the $\mathrm{WO}_{3}$ reflection, but the relative intensities of the various $\mathrm{WO}_{3}$ reflections in any one XRD spectrum show little sensitivity to these changes, and the main factor behind these trends is likely to be the amount of deposited material. By way of comparison, the corresponding ratio for the case of a PLD-free film grown for the same duration at $T_{\text {sub }}=700{ }^{\circ} \mathrm{C}$ and $p \mathrm{O}_{2}=10$ mTorr is 0.22 .

TEM analysis reveals further subtleties. The low resolution TEM image of material broken from the with-PLD sample (Fig. 4(a)) provides an estimate of the NR lengths (which reach $\ell \sim 700 \mathrm{~nm})$ and diameters. The latter vary among the different NRs, spanning the range $50-80 \mathrm{~nm}$, but remain fairly constant along the length of any one NR. Fig. 4(b) and (c) show, respectively, a HRTEM image from near the tip of a single NR and the SAED pattern recorded from this NR. The latter is consistent with a (001) orientation of cubic- $\mathrm{WO}_{3}$ and a [100] growth direction - in accord with the XRD data (Fig. 3(c)) - while the obvious streaking in the (020) reflection implies the presence of numerous stacking faults in this direction. The closely spaced diffraction spots apparent in the diffraction streaks also suggest a long range ordering of the stacking faults. These observations are consistent with the HRTEM image (Fig. 4(b)), which shows single crystal regions with clearly defined fringe spacings of $d \sim 0.38 \mathrm{~nm}$ (characteristic of cubic- $\mathrm{WO}_{3}$ ) separated by obvious stacking faults where the registry of the planes slips by, for example, half a fringe spacing. Such herring-bone-like patterns, which imply the presence of multiple superimposed crystallographic domains bounded by stacking faults, or crystallographic shears, have also been reported previously ${ }^{16,30,31}$ and are a characteristic signature of sub-stoichiometric tungsten trioxide $\left(\mathrm{WO}_{3-\delta}\right)$.

\subsection{Growth on Ta substrates}

Similar process conditions enable growth of dense arrays of $\mathrm{WO}_{x}$ NRs on Ta substrates. Optimal conditions were established as $T_{\text {sub }} \sim 700{ }^{\circ} \mathrm{C}$ and $p \mathrm{O}_{2}=50$ mTorr, as illustrated by the SEM image of a with-PLD sample grown for $t=45 \mathrm{~min}$ shown in Fig. 5(c). As with a $\mathrm{W}$ substrate, the form of the deposited material is very sensitive to the choice of $T_{\text {sub }}$; deposition for the same $t$ and with the same $p \mathrm{O}_{2}$ but lower $T_{\text {sub }}$ yielded either sparse clumps of NRs or none at all (Fig. 5(a) and (b)). Deposition at $T_{\text {sub }} \sim 700{ }^{\circ} \mathrm{C}$ but with lower $p \mathrm{O}_{2}$ (e.g. 10 mTorr) again yielded dense NR arrays, but with smaller aspect ratio (as illustrated in Fig. 5(d)). XRD analysis reveals that the dominant phase evolves with $T_{\text {sub }}$. Fig. 6 shows XRD data from several samples grown at different $T_{\text {sub }}$ but constant $p \mathrm{O}_{2}=50$ mTorr; XRD spectra of samples grown in $p \mathrm{O}_{2}=$ 10 mTorr show all the same trends. All peaks in the XRD spectra of samples prepared at $T_{\text {sub }}<550{ }^{\circ} \mathrm{C}$ are attributable to the Ta foil substrate - consistent with the amorphous appearance of the $\mathrm{WO}_{x}$ layer in the corresponding SEM image (Fig. 5(a)). Additional reflections are observed in the XRD spectra of samples deposited at $T_{\text {sub }} \geq 550{ }^{\circ} \mathrm{C}$, all of which are seen (by SEM) to support NRs. None of the additional peaks can be assigned to cubic- $\mathrm{WO}_{3}$ (Fig. 3), but most align well with documented low-order reflections from the hexagonal phase of $\mathrm{WO}_{3}$ (JCPDS no. 33-1387).

Once again, however, TEM analysis reveals further subtleties. Low-resolution TEM images of NRs grown by PLD on Ta for $t=45 \mathrm{~min}$ at $T_{\mathrm{sub}}=700{ }^{\circ} \mathrm{C}$ and $p \mathrm{O}_{2}=50$ mTorr (Fig. 7(a)) show clear similarities with those of the NRs grown on W (Fig. 4(a)), but HRTEM and SAED investigations imply the
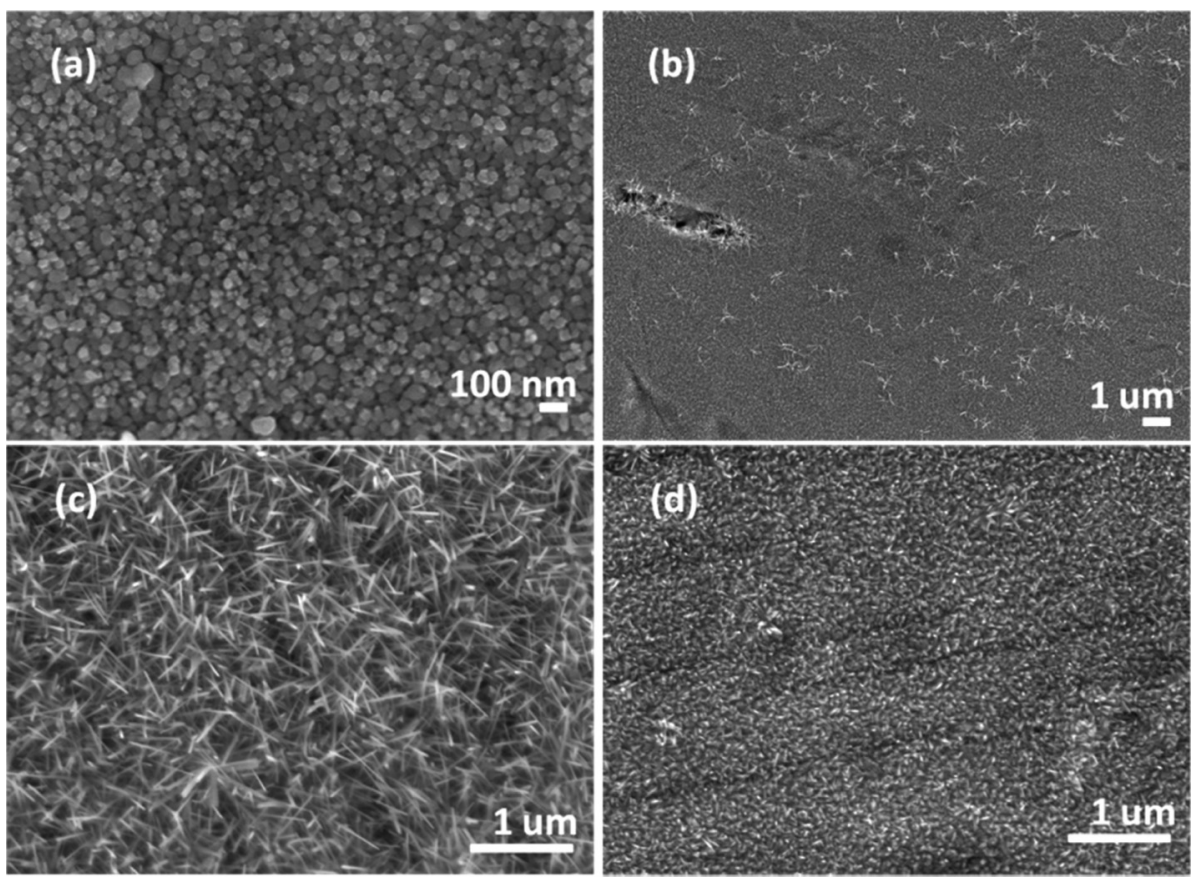

Fig. 5 SEM images of $\mathrm{WO}_{x}$ layers grown by $193 \mathrm{~nm}$ ablation of the $\mathrm{WO}_{3}$ target for $t=45 \mathrm{~min}$ on Ta substrates under the following conditions of $\mathrm{T}_{\text {sub }}$ and $\mathrm{pO}_{2}$ : (a) $450^{\circ} \mathrm{C}, 50 \mathrm{mTorr}$; (b) $550^{\circ} \mathrm{C}, 50 \mathrm{mTorr}$; (c) $700^{\circ} \mathrm{C}, 50 \mathrm{mTorr}$; (d) $700{ }^{\circ} \mathrm{C}, 10 \mathrm{mTorr}$. 


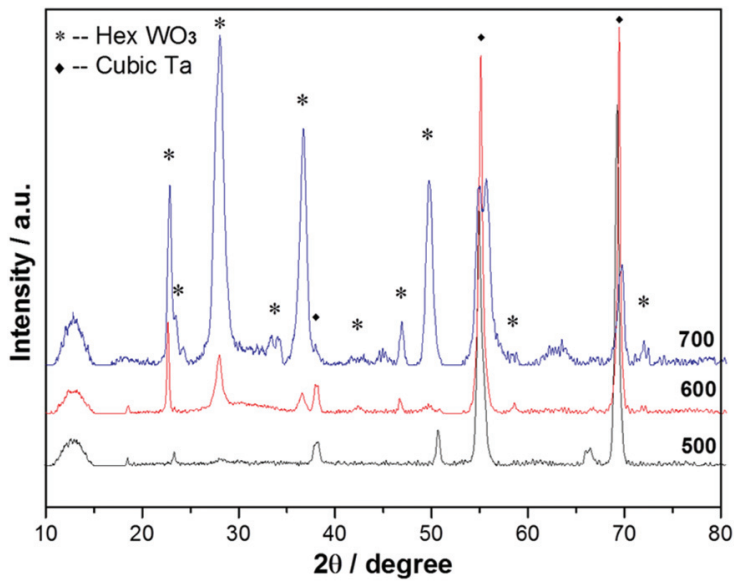

Fig. 6 XRD spectra of $\mathrm{WO}_{x}$ layers grown on Ta by $193 \mathrm{~nm}$ ablation of the $\mathrm{WO}_{3}$ target for $t=45 \mathrm{~min}$ in $\mathrm{pO}_{2}=50 \mathrm{mTorr}$ at $T_{\text {sub }}=500,600$ and $700{ }^{\circ} \mathrm{C}$. Diffraction peaks attributable to hexagonal- $\mathrm{WO}_{3}$ are evident in spectra of samples grown at $T_{\text {sub }} \geq 550^{\circ} \mathrm{C}$ as indicated by the symbols above the upper most trace.
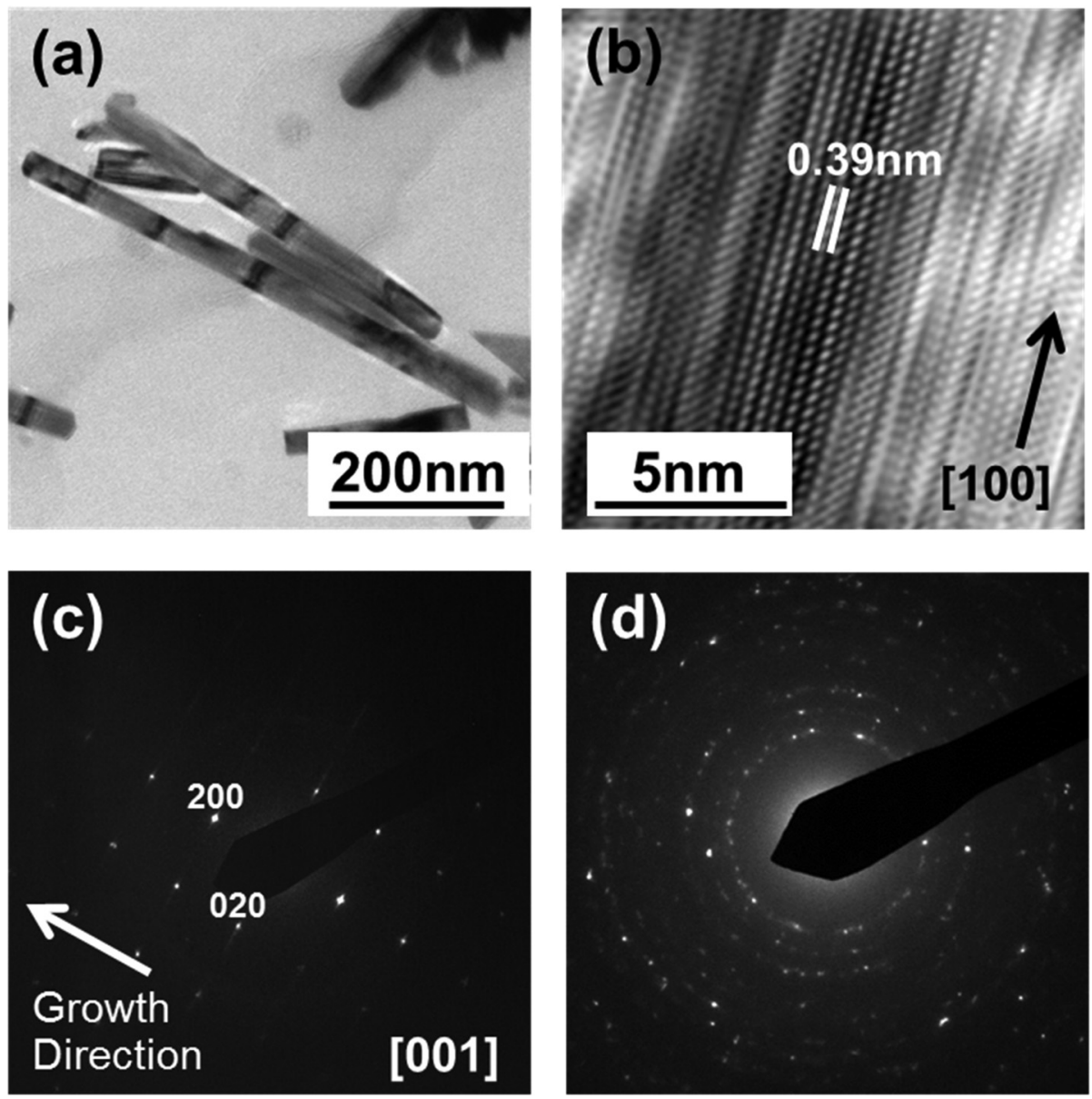

Fig. 7 (a) Low resolution TEM image of NRs broken from the $W_{x}$ layer grown on a Ta substrate at $T_{\text {sub }}=700{ }^{\circ} \mathrm{C}$ by $193 \mathrm{~nm}$ ablation of the WO target in the presence of $\mathrm{pO}_{2}=50 \mathrm{mTorr}$ for $t=45 \mathrm{~min}$. (b) HRTEM and (c) SAED images taken from a single NR, illustrating the cubic-WO 3 microstructure. (d) SAED image taken from a clump of NRs; the ring separations fit well with that expected for hexagonal $\mathrm{WO}_{3}$. 

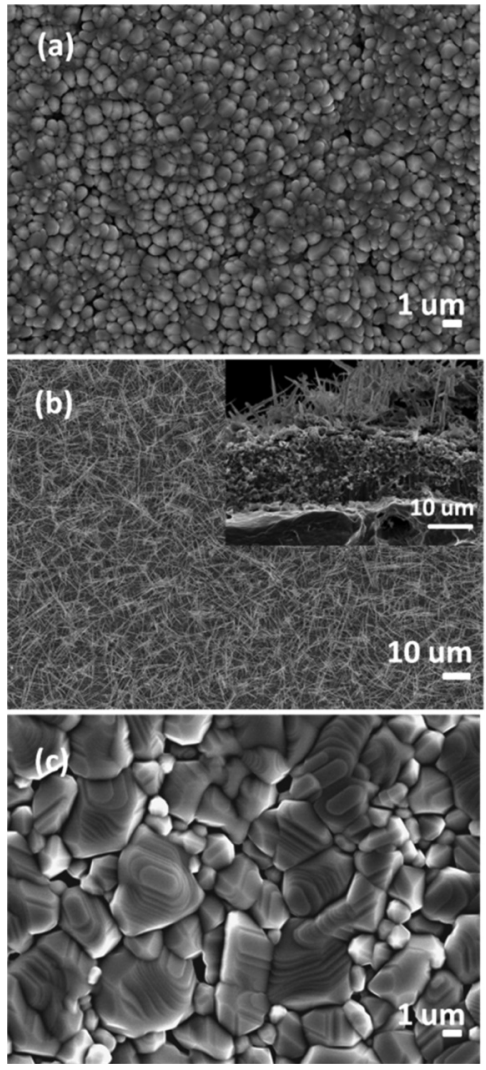

Fig. 8 SEM images of $\mathrm{WO}_{x}$ layers grown by $193 \mathrm{~nm}$ ablation of the $\mathrm{WO}_{3}$ target for $t=45 \mathrm{~min}$ on a $\mathrm{Cu}$ substrate in the presence of $\mathrm{pO}_{2}=$ 10 mTorr at $T_{\text {sub }}=$ (a) $400{ }^{\circ} \mathrm{C}$; (b) $500{ }^{\circ} \mathrm{C}$; and (c) $600{ }^{\circ} \mathrm{C}$. The crosssection image of the deposit grown at $T_{\text {sub }}=500{ }^{\circ} \mathrm{C}$ (inset in panel (b)) shows a tangle of poorly aligned NRs emerging from a dense thatch of underlying material.

samples were deposited under $p \mathrm{O}_{2}=10 \mathrm{mTorr}$ for $t=45 \mathrm{~min}$. The morphology of the deposited material is very sensitive to $T_{\text {sub }}$, and ranges from a 'cobbled' coating at $T_{\text {sub }}=400{ }^{\circ} \mathrm{C}$, through an array of fine NRs at $T_{\text {sub }}=500{ }^{\circ} \mathrm{C}$, to a film composed of larger crystallites at $600{ }^{\circ} \mathrm{C}$. The cross-section image (Fig. 8(b), inset) shows that the NRs on $\mathrm{Cu}$ are less dense than those on Ta or $\mathrm{W}$ substrates, and sit on a dense underlying thatch of deposited material. The very different appearance of these NRs ( $c f$. those grown on $\mathrm{W}$ or Ta substrates) is shown more clearly by the image of an as-grown tangle of NRs (Fig. 9(a)) and of a 'single' NR in Fig. 9(b). The NR has a 'treelike' appearance, with first- (and in some cases second-) generation 'daughter' NRs emerging perpendicular to the shaft of the parent NR. These dendritic structures are somewhat reminiscent of those reported in prior studies where $\mathrm{W}$ foil (covered by a $\mathrm{SiO}_{2}$ plate) was heated in $\mathrm{Ar}$ at $1600{ }^{\circ} \mathrm{C},{ }^{33}$ where $\mathrm{W}$ powder was heated in oxygen to $1400-1450{ }^{\circ} \mathrm{C},{ }^{6,34}$ and where PLD-grown $\mathrm{WO}_{x}$ films were subsequently thermally annealed in vacuum and then in air. ${ }^{35}$ The daughter NRs in the present work appear to grow from an edge of the parent NR, as shown in the inset to Fig. 9(b), rather than the face (as suggested by some of these prior studies). Compared with the $\mathrm{WO}_{x}$ NRs grown on $\mathrm{W}$ and $\mathrm{Ta}$, the NRs grown on $\mathrm{Cu}$ are
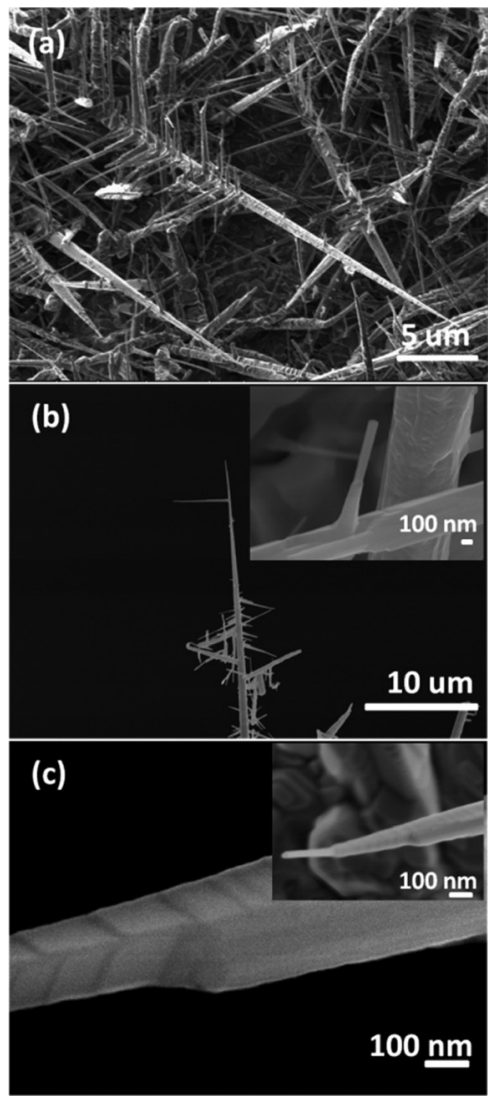

Fig. 9 Progressively higher resolution SEM images of $\mathrm{WO}_{x}$ NRs grown on a Cu substrate in the presence of $\mathrm{pO}_{2}=10 \mathrm{mTorr}$ by $193 \mathrm{~nm}$ ablation of the $\mathrm{WO}_{3}$ target for $t=45 \mathrm{~min}$ at $T_{\text {sub }}=500^{\circ} \mathrm{C}$ : (a) an as-grown tangle of tree-like NRs; (b) a 'single' NR demonstrating the emergence of first (and in some cases second) generation daughter NRs at right angles to and from the edge of (see inset) the shaft of the parent NR; (c) detail of the end of a single NR shaft, illustrating obvious faceting and tapered morphology in the growth direction.

'macroscopic': many $\mu \mathrm{m}$ in length, generally much thicker at the base, and clearly tapering in the growth direction; many terminate with a narrow tip (Fig. 9(c)).

As Fig. 10 shows, the as-grown material exhibits a simple XRD spectrum with clear peaks at $2 \theta=15.2,18.1,31.6$ and $36.2^{\circ}$ that are not attributable to the $\mathrm{Cu}$ substrate. We have not succeeded in matching these with any documented $\mathrm{WO}_{x}$ structure, though we note that peaks at $\sim 18^{\circ}$ and $\sim 37^{\circ}$ have previously been identified as (111) and (222) reflections of orthorhombic $\mathrm{WO}_{3}{ }^{36}$ As noted above, the XRD measurements inherently sample a large $\left(\sim 1 \mathrm{~cm}^{2}\right)$ area, so the relative contributions made by the dendritic NRs and the underlying thatch to the total XRD spectrum is unclear. The SAED patterns shown in Fig. 11, in contrast, are taken from the tapered tip of a single NR and are clearly consistent with a cubic structure with lattice parameter $a=0.38 \mathrm{~nm}$. Panel (a) in Fig. 11 shows a (001) diffraction pattern (i.e. with an [001] zone axis parallel to the electron beam direction) with the NR growth direction [100] indicated by the arrow, while Fig. 11(b) shows the corresponding SAED pattern taken along the [101] axis (obtained by 


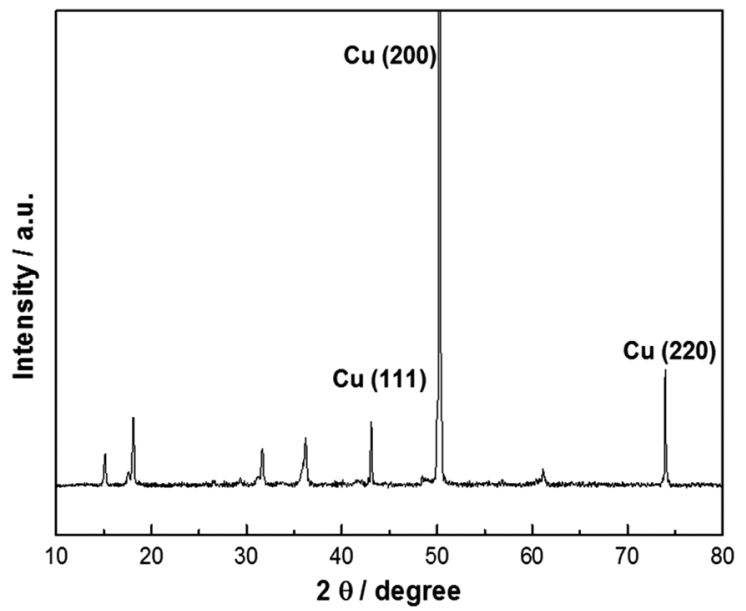

Fig. 10 XRD spectrum of the $\mathrm{WO}_{x}$ layer grown on $\mathrm{Cu}$ by $193 \mathrm{~nm}$ ablation of the $\mathrm{WO}_{3}$ target for $t=45 \mathrm{~min}$ in $\mathrm{pO}_{2}=10 \mathrm{mTorr}$ and at $T_{\text {sub }}=$ $500{ }^{\circ} \mathrm{C}$. Peaks attributable to the $\mathrm{Cu}$ substrate are assigned, leaving four unassigned peaks that we attribute to $\mathrm{WO}_{x}$.

tilting the $\mathrm{NR}$ by $45^{\circ}$ about [010], such that the (040) reflection is common to both patterns). The appearance of the (020) reflection in the [101] pattern but not in the [001] pattern is consistent with $\{200\}$ reflections being kinematically forbidden, with excitation depending on double diffraction routes which are present in the [101], but not in the [001], orientation.

Fig. 12(a) and (b) show an HRTEM image and an SAED pattern taken from the ends of other tapered crystals like that shown in the inset to Fig. 8(c). The SAED pattern is clearly different from those in Fig. 11 but if, for simplicity, we take the NR axis to be a [100] axis of the tip crystal, we can identify the main reflections nominally as $\{400\}$-type, with spacings of $0.19 \mathrm{~nm}$ that match well with the spacing of the $\{400\}$ reflections identified in Fig. 11. The pair of spots arrowed in Fig. 12(b) can be reproduced by a model of the type shown in Fig. 12(d), based on $\mathrm{W}_{n} \mathrm{O}_{3 n-1}$ structures, where crystallographic shear faults separate $n$ planes of corner sharing $\mathrm{WO}_{6}$ octahedra. ${ }^{30,31}$ The structure and simulated diffraction pattern shown in Fig. $12(\mathrm{~d})$ and (c) correspond to $n=4$, i.e. $\mathrm{W}_{4} \mathrm{O}_{11}$. Experimentally, there is prominent streaking perpendicular to the NR axis, rather than the regular superlattice in Fig. 12(c), suggesting that $n$ and the corresponding stoichiometry vary on a fine scale. These features are consistent with the lattice image in Fig. 12(a) (taken from a different crystal), which shows small regions that display a regular and approximately square cross-grating pattern, with $0.38 \mathrm{~nm}$ spacing, as well as an irregular structure perpendicular to the NR axis.

Selected $\mathrm{WO}_{x}$ samples grown on $\mathrm{Cu}$ were also investigated by XPS though, as with XRD, we caution that XPS analysis must return a superposition of compositional information for both the NRs and the underlying thatch. Expanded views of the $\mathrm{W}$ 4f and $\mathrm{O}$ 1s binding energy regions are shown in Fig. 13. The former can be decomposed (Fig. 13(a)) into a doublet of doublets, attributable to the $4 f_{7 / 2}$ and $4 f_{5 / 2}$ peaks of both the $\mathrm{W}^{6+}$ and $\mathrm{W}^{5+}$ oxidation states. ${ }^{37,38}$ The presence of two oxidation states provides further indication that the material is sub-stoichiometric $\mathrm{WO}_{3-\delta}$, as does the obvious tailing of the $\mathrm{O}$ 1s peak to higher binding energies (Fig. 13(b)). The illustrative decomposition shown in Fig. 13(b), along with an assumed assignment of the 530.2 and $531.4 \mathrm{eV}$ peaks to $\mathrm{O}$ atoms in, respectively, stoichiometric $\mathrm{WO}_{3}$ and sub-stoichiometric $\mathrm{WO}_{3-\delta},{ }^{39,40}$ implies a mean composition with $\delta \approx 0.2$.

\subsection{Raman spectroscopy of as-grown $\mathrm{WO}_{x}$ samples}

Features in Raman spectra of $\mathrm{WO}_{x}$ samples are traditionally viewed in three separate wavenumber regions, depending on their physical origin. Peaks at wavenumbers $<200 \mathrm{~cm}^{-1}$ are associated with lattice modes (tilting or translations of the $\mathrm{WO}_{6}$ octahedra); features in the $200-400 \mathrm{~cm}^{-1}$ region can be assigned to $\mathrm{W}-\mathrm{O}-\mathrm{W}$ stretch and/or $\mathrm{O}-\mathrm{W}-\mathrm{O}$ bending modes; while $\mathrm{O}-\mathrm{W}-\mathrm{O}$ stretching modes typically fall in the $600-900 \mathrm{~cm}^{-1}$ range. ${ }^{41,42}$ The Raman spectrum of the polycrys-

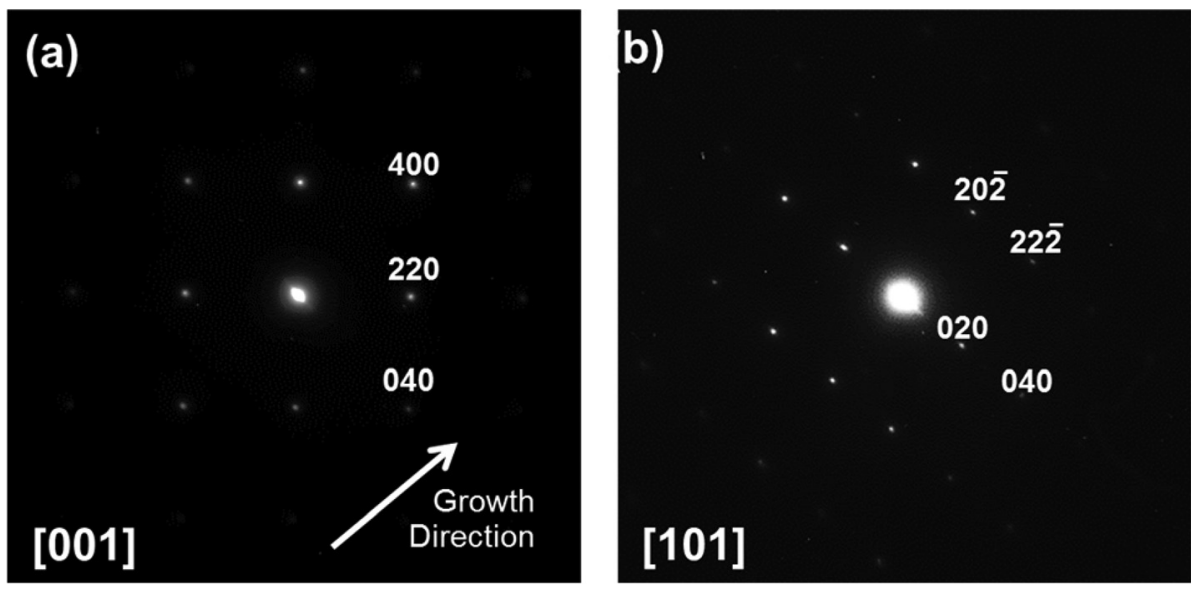

Fig. 11 SAED patterns recorded from near the tip of a single $\mathrm{WO}_{x} \mathrm{NR}$ grown on Cu by $193 \mathrm{~nm}$ ablation of the $\mathrm{WO}_{3}$ target for $t=45 \mathrm{~min}$ in $p \mathrm{O}_{2}=$ $10 \mathrm{mTorr}$ and at $T_{\text {sub }}=500^{\circ} \mathrm{C}$. Image (a) shows a (001) diffraction pattern (i.e. with an [001] zone axis parallel to the electron beam direction), with the arrow indicating the NR growth direction [100], while (b) shows the corresponding pattern taken along the [101] axis (obtained by tilting the NR by $45^{\circ}$ about [010]). The (040) reflection is thus common to both patterns. 

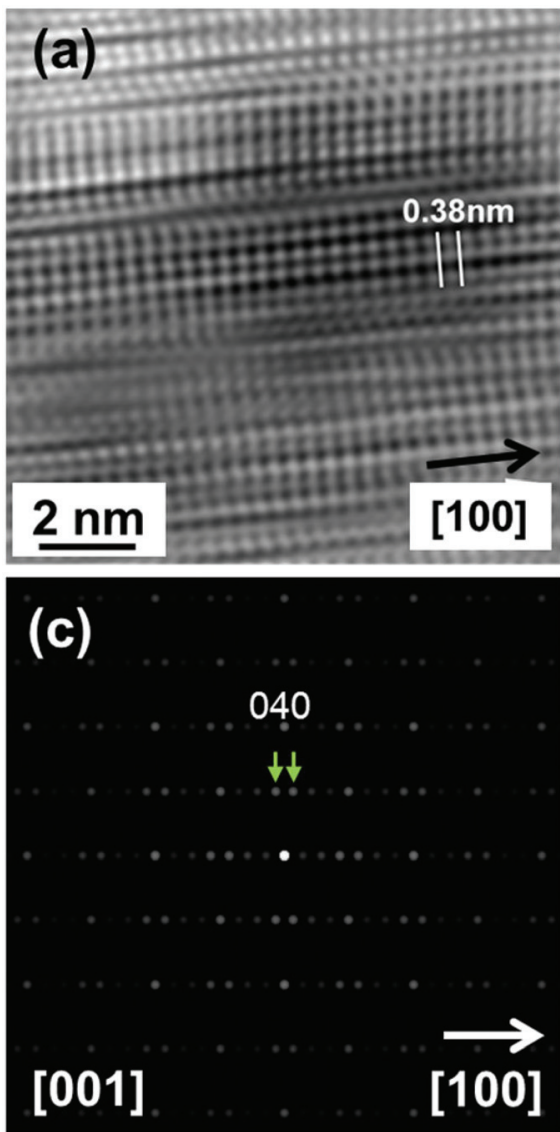

Fig. 12 (a) HRTEM and (b) SAED images recorded near the tip of single $\mathrm{WO}_{x}$ NRs grown on Cu by $193 \mathrm{~nm}$ ablation of the WO 3 target for $t=45 \mathrm{~min}$ in $\mathrm{pO}_{2}=10 \mathrm{mTorr}$ and at $T_{\text {sub }}=500^{\circ} \mathrm{C}$, (c) simulated diffraction pattern for the model structure shown in (d), a unit cell for a $\mathrm{W}_{4} \mathrm{O}_{11}$ structure where crystallographic shear faults separate 4 planes of corner sharing $\mathrm{WO}_{6}$ octahedra. The two arrowed reflections in (c) can be compared with those arrowed in (b).

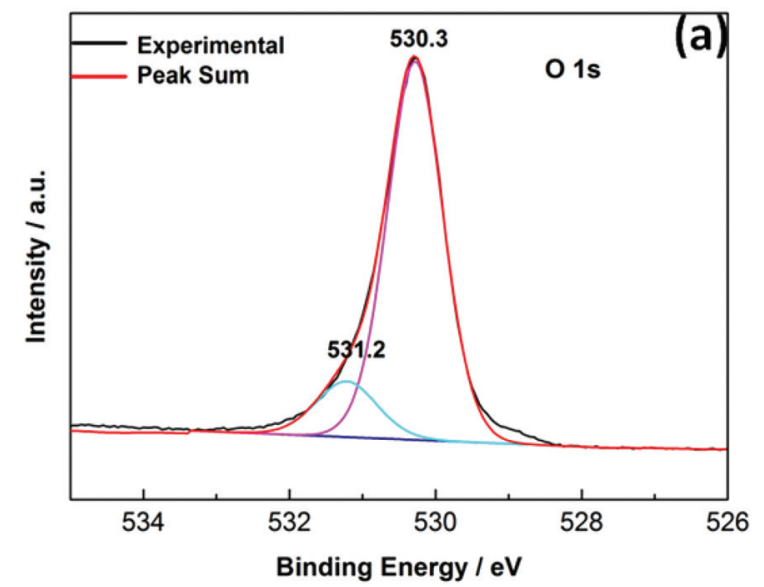

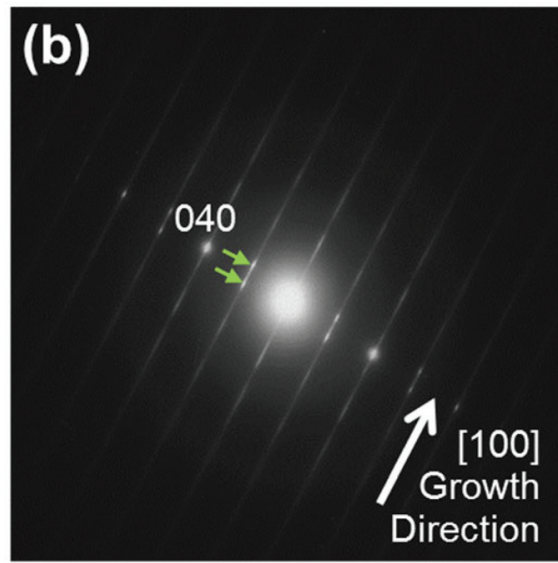

(d)

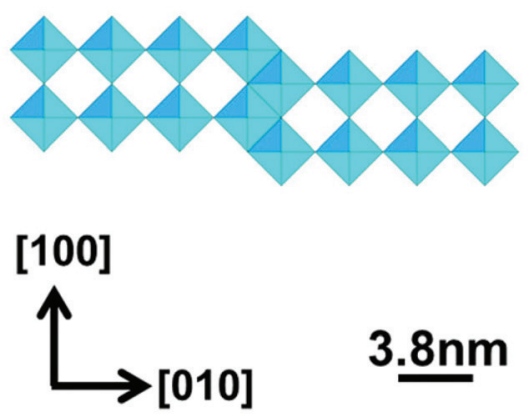

Fig. 13 Detailed views of the $\mathrm{O} 1 \mathrm{~s}$ and $\mathrm{W} 4 \mathrm{f}$ peaks in the X-ray photoelectron spectrum of the WO $\mathrm{O}_{x}$-on-Cu sample grown by $193 \mathrm{~nm}$ ablation of the $\mathrm{WO}_{3}$ target for $t=45 \mathrm{~min}$ in $\mathrm{pO}_{2}=10 \mathrm{mTorr}$ and at $T_{\text {sub }}=500^{\circ} \mathrm{C}$, decomposed as described in the text.

talline target recorded under $632.8 \mathrm{~nm}$ illumination (curve (a) in Fig. 14) shows clear features at 273, 324, 716 and $807 \mathrm{~cm}^{-1}$, all of which are characteristic of monoclinic $\mathrm{WO}_{3}$. However, the additional weak features at 182 and $569 \mathrm{~cm}^{-1}$ (which match no documented Raman peaks of monoclinic $\mathrm{WO}_{3}$ ) hint 


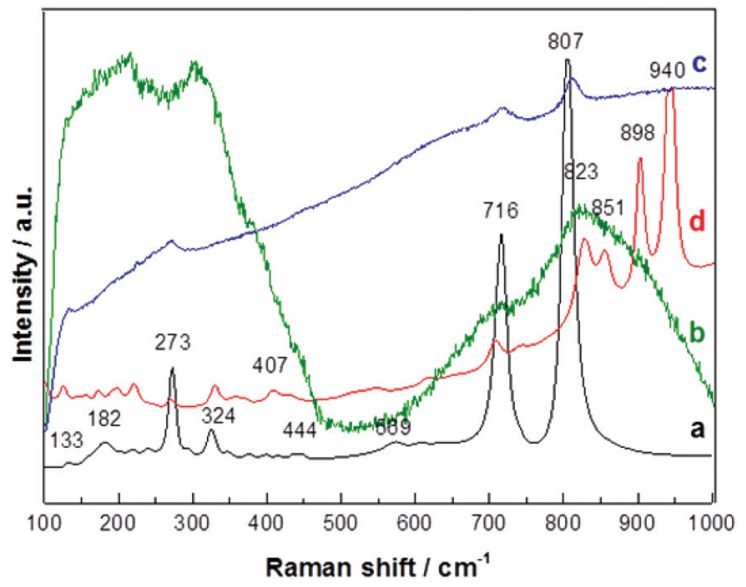

Fig. 14 Raman spectra (632.8 $\mathrm{nm}$ excitation) of (a) the polycrystalline $\mathrm{WO}_{3}$ target and of the NR-rich $\mathrm{WO}_{x}$ deposits grown on (b) W, (c) Ta and (d) Cu substrates by $193 \mathrm{~nm}$ ablation of the $\mathrm{WO}_{3}$ target for $t=45 \mathrm{~min}$ using $\mathrm{pO}_{2}$ and $T_{\text {sub }}$ values appropriate for optimal NR growth in each case. Wavenumbers of many of the more prominent peaks are superimposed above the relevant trace.

and $807 \mathrm{~cm}^{-1}$, but the breadth of these features (which must involve scattering from both the NRs and the underlying thatch) limits the utility of Raman spectroscopy as a compositional diagnostic in these cases. Curve (d) shows much more structure, with the peaks at high wavenumber particularly notable. Based on the previous literature ${ }^{41}$ it is tempting to assign the 823 and $851 \mathrm{~cm}^{-1}$ features to $\mathrm{O}-\mathrm{W}-\mathrm{O}$ stretching modes, with the shift to higher wavenumber reflecting some shortening (stiffening) of the relevant bonds between the edge sharing octahedra. The $940 \mathrm{~cm}^{-1}$ feature is associated with terminal $\mathrm{W}=\mathrm{O}$ bonds. This feature is commonly observed in the Raman spectra of nanocrystalline $\mathrm{WO}_{x}$ samples; indeed, arguments have appeared ${ }^{43}$ suggesting that its intensity relative to that of the $\mathrm{O}-\mathrm{W}-\mathrm{O}$ stretch bands can be used as a measure of surface-to-volume ratio or cluster size. The present data may lend some support to this argument given that these features are particularly evident in the Raman spectrum of material deposited on a $\mathrm{Cu}$ substrate which, as Fig. 9 showed, is rich in the dendritic NR structures.

\subsection{Field emission measurements on as-grown $\mathrm{WO}_{x}$ samples}

Field emission (FE) measurements were performed at room temperature in a test chamber (base pressure $\sim 5 \times 10^{-7}$ Torr) that has been described previously. ${ }^{44}$ The $\mathrm{WO}_{x}$ samples acted as the cathode, the anode comprised a phosphor screen coated with a $10 \mathrm{~nm}$ layer of gold, and the cathode-anode separation was maintained at $d=420 \mu \mathrm{m}$ using a silica spacer and an aperture that defines an effective sampling area $A=0.076 \mathrm{~cm}^{2}$. The voltage, $V$, applied to each sample was ramped up and down once and the emission current, $I$, measured to obtain an initial $I-V$ curve, and the sample was then 'conditioned' by cycling a further 5 times to encourage the release of any impurities.

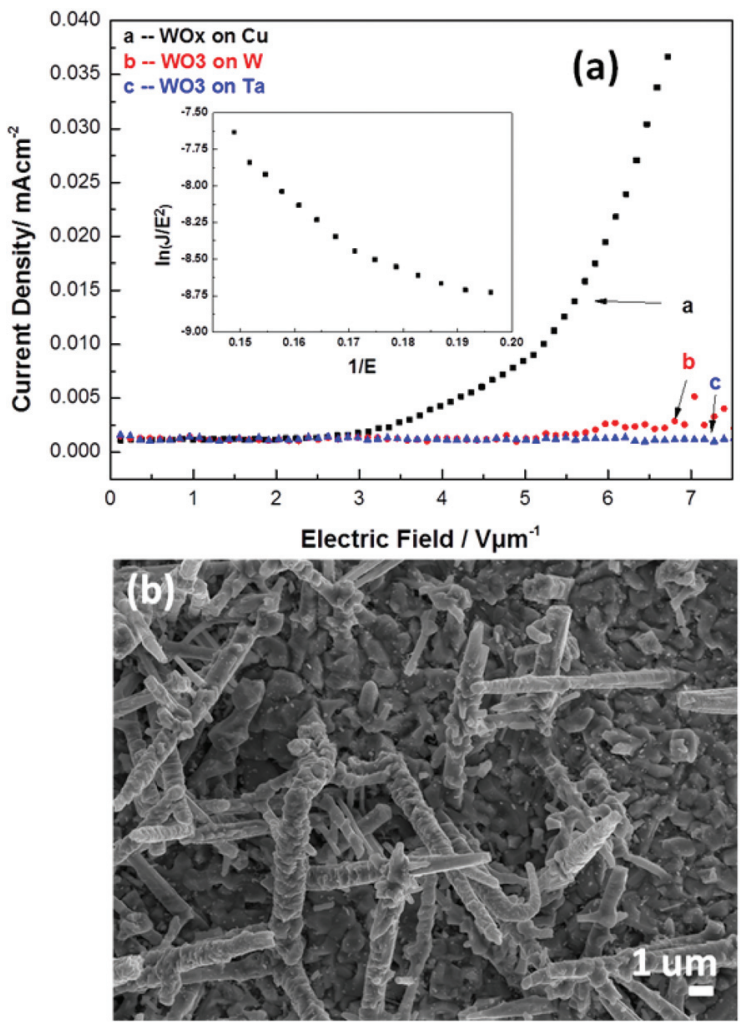

Fig. 15 (a) Field emission current vs. applied field plot for a NR-rich $\mathrm{WO}_{x}$ deposit on a $\mathrm{Cu}$ substrate grown under conditions as for the material shown in Fig. 9(a), along with the corresponding Fowler-Nordheim plot (inset). (b) SEM image of such a sample after application of a $12 \mathrm{~V} \mu \mathrm{m}^{-1}$ field, illustrating the destruction of the finer nanostructures caused by over-driving the emission.

The $I-V$ data shown in Fig. 15(a) for NR-rich $W_{x}$ samples grown on $\mathrm{W}, \mathrm{Ta}$ and $\mathrm{Cu}$ substrates are the average values returned from the next 10 up-down cycles. As is customary, we plot the emission current density, $J\left(=I / A\right.$, in $\left.\mathrm{mA} \mathrm{cm}^{-2}\right) v s$. electric field, $E\left(=V / d\right.$, in $\left.\mathrm{V} \mu \mathrm{m}^{-1}\right)$. Only the sample grown on $\mathrm{Cu}$ exhibits encouraging FE properties, with a turn on field (which we choose to define as the field yielding an emission current density of $10 \mu \mathrm{A} \mathrm{cm}^{-2}$ ) of $\sim 5 \mathrm{~V} \mathrm{\mu m}^{-1}$-comparable to that reported for nanostructured $\mathrm{WO}_{x}$ samples in other recent studies. ${ }^{45-47}$ The associated Fowler-Nordheim plot $^{48}$ (i.e. plot of $\ln \left(J / E^{2}\right)$ vs. 1/E, which is shown as an inset to Fig. 15(a)), shows two linear regions (with a steeper slope in the high field region) pivoting at $1 / E \sim 0.17 \mathrm{~V}^{-1} \mu \mathrm{m}$. The form of this plot is reminiscent of that reported in a previous study of $\mathrm{FE}$ from $\mathrm{WO}_{x}$ nanowires grown on electrochemically sharpened tungsten tips ${ }^{49}$ and, as in that case, can plausibly be attributed to the disperse spread of NR lengths, diameters and orientations supported by the sample.

The stability of the FE from a NR-rich $\mathrm{WO}_{x}$ on $\mathrm{Cu}$ sample

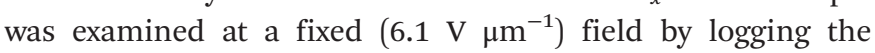
current every $1.3 \mathrm{~s}$. Apart from some transient spikes, the emission remained stable at $\sim 15 \mu \mathrm{A}$ (fluctuating by $<10 \%$ ) over the duration of the measurement ( 35 hours). SEM analysis of this sample post FE testing showed no discernible change to the 
sample morphology, but ramping the field up to $12 \mathrm{~V} \mu \mathrm{m}^{-1}$ resulted in an immediate and dramatic drop in emission intensity. The SEM image of this over-driven sample (Fig. 15(b)) reveals large structural changes; the finer tips and branches have been destroyed, leaving just the parent NR shafts with a much rougher surface morphology.

\section{Conclusions}

The present study reports the growth of tungsten oxide NRs by $193 \mathrm{~nm}$ pulsed laser deposition in a low background pressure of oxygen, and subsequent characterisation of the as-grown material by SEM and HRTEM, SAED, XRD, Raman and XPS. The morphology of the deposited material is found to be sensitively dependent upon the choice of deposition conditions, including the substrate material itself. HRTEM analysis shows that NRs formed on $\mathrm{W}$, Ta and $\mathrm{Cu}$ substrates each grow along the [100] direction and display obvious stacking faults running along this direction. Such faults also reveal themselves by streaking in the SAED pattern, perpendicular to the growth axis - implying that the NR composition is sub-stoichiometric $\mathrm{WO}_{3-\delta}$ in each case. The NR morphologies are very different, however. NRs formed on W or Ta substrates are short (100 s of $\mathrm{nm}$ in length) and display uniform cross-sections, while those grown on the $\mathrm{Cu}$ substrate are typically longer, thicker, tapered, and display a branched, dendritic microstructure. Only these latter NRs are found to give significant field emission.

\section{Acknowledgements}

The authors are grateful to EPSRC, the China Scholarship Council, the National Science Foundation of China (grant no. 61176005 and 61006001) and the Higher Education Commission of Pakistan for financial support, and to J.N. Hart, J.A. Jones, Dong Liu, M.Z. Othman, K.N. Rosser, T.B. Scott, J.A. Smith, B.S. Truscott and Y.S. Zou for their many and varied contributions to the described work.

\section{References}

1 H. D. Zheng, J. Z. Ou, M. S. Strano, R. B. Kaner, A. Mitchell and K. Kalantar-Zadeh, Adv. Funct. Mater., 2011, 21, 2175, and references therein.

2 C. G. Granqvist, Handbook of Inorganic Electrochromic Materials, Elsevier, New York, 1995.

3 G. A. Niklasson and C. G. Granqvist, J. Mater. Chem., 2007, $17,127$.

4 See, for example, Z. G. Zhao and M. Miyauchi, Angew. Chem., Int. Ed., 2008, 47, 7051.

5 See, for example, X. Liu, F. Wang and Q. Wang, Phys. Chem. Chem. Phys., 2012, 14, 7894.
6 A. Ponzoni, E. Comini, G. Sberveglieri, J. Zhou, S. Z. Deng, N. S. Xu, Y. Ding and Z. L. Wang, Appl. Phys. Lett., 2006, 88, 203101.

7 R. S. Devan, R. A. Patil, J. H. Lin and Y. R. Ma, Adv. Funct. Mater., 2012, 22, 3326, and references therein.

8 See, for example, H. Zheng, Y. Tachibana and K. KalantarZadeh, Langmuir, 2010, 26, 19148.

9 J. G. Allpress, R. J. D. Tilley and M. J. Sienko, J. Solid State Chem., 1971, 3, 440.

10 Z. J. Gu, T. Y. Zhai, B. F. Gao, X. H. Zheng, Y. B. Wang, H. B. Fu, Y. Ma and J. N. Yao, J. Phys. Chem. B, 2006, 110, 23829.

11 J. M. Wang, E. Khoo, P. S. Lee and J. Ma, J. Phys. Chem. C, 2008, 112, 14306.

12 K. Kalantar-Zadeh, A. Vijayaraghavan, M.-H. Ham, H. D. Zheng, M. Breedon and M. S. Strano, Chem. Mater., 2010, 22, 5660.

13 H. W. Zhang, G. T. Duan, Y. Li, X. X. Xu, Z. F. Dai and W. P. Cai, Cryst. Growth Des., 2012, 12, 2646.

14 H. W. Zhang, Y. Li, G. T. Duan, G. Q. Liu and W. P. Cai, CrystEngComm, 2014, 16, 2491.

15 J. Thangala, S. Vaddiraju, R. Bogale, R. Thurman, T. Powers, B. Deb and M. K. Sunkara, Small, 2007, 3, 890.

16 A. M. Smith, M. G. Kast, B. A. Nail, S. Aloni and S. W. Boettcher, J. Mater. Chem. A, 2014, 2, 6121.

17 F. Mitsugi, E. Hiraiwa, T. Ikegami, K. Ebihara and R. K. Thareja, Jpn. J. Appl. Phys., Part 1, 2002, 41, 5372.

18 T. Aoki, T. Matsushita, A. Suzuki, K. Tanabe and M. Okuda, J. Vac. Sci. Technol., A, 2005, 23, 1325.

19 C. V. Ramana, S. Utsunomiya, R. C. Ewing, C. M. Julien and U. Becker, J. Phys. Chem. B, 2006, 110, 10430.

20 Y. Suda, H. Kawasaki, T. Ohshima and Y. Yagyuu, Thin Solid Films, 2008, 516, 4397.

21 K. J. Lethy, D. Beena, R. V. Kumar, V. P. M. Pillai, V. Ganesan and V. Sathe, Appl. Surf. Sci., 2008, 254, 2369.

22 N. Santo, M. Filipescu, P. M. Ossi and M. Dinescu, Appl. Phys. A, 2010, 101, 325.

23 Y. S. Zou, Y. C. Zhang, D. Lou, H. P. Wang, L. Gu, Y. H. Dong, K. Dou, X. F. Song and H. B. Zeng, J. Alloys Compd., 2014, 583, 465.

24 M. H. Yaacob, J. Z. Ou, W. Wlodarski, C. S. Kim, J. Y. Lee, Y. H. Kim, C. M. Oh, K. P. Dhakal, J. Y. Kim and J. H. Kang, J. Korean Phys. Soc., 2012, 60, 393.

25 M. Z. Ahmad, J. Kang, A. S. Zoolfakar, A. Z. Sadek and W. Wlodarski, J. Nanosci. Nanotechnol., 2013, 13, 8315.

26 Y. Sun, G. M. Fuge and M. N. R. Ashfold, Chem. Phys. Lett., 2004, 396, 21.

27 G. M. Fuge, T. M. S. Holmes and M. N. R. Ashfold, Chem. Phys. Lett., 2009, 479, 125.

28 T. Tokunaga, T. Kawamoto, K. Tanaka, N. Nakamura, Y. Hayashi, K. Sasaki, K. Kuroda and T. Yamamoto, Nanoscale Res. Lett., 2012, 7, 85.

29 S. G. Jeon and J. J. Yong, J. Mater. Res., 2008, 23, 132.

30 T. Miyano, M. Iwanishi, C. Kaito and M. Shiojiri, Jpn. J. Appl. Phys., 1983, 22, 863. 
31 J. Sloan, J. L. Hutchinson, R. Tenne, Y. Feldman, T. Tsirlina and M. Honyonfer, J. Solid State Chem., 1990, 144, 100.

32 B. Gerand, G. Nowogrocki, J. Guenot and M. Figlarz, J. Solid State Chem., 1979, 29, 429.

33 Y. Q. Zhu, W. B. Hu, W. K. Hsu, M. Terrones, N. Grobert, J. P. Hare, H. W. Kroto, D. R. M. Walton and H. Terrones, Chem. Phys. Lett., 1999, 309, 327.

34 J. Zhou, Y. Ding, S. Z. Deng, L. Gong, N. S. Xu and Z. L. Wang, Adv. Mater., 2005, 17, 2107.

35 A. Ponzoni, V. Russo, A. Bailini, C. S. Casari, M. Ferroni, A. Li Bassi, A. Migliori, V. Morandi, L. Ortolani, G. Sberveglieri and C. E. Bottani, Sens. Actuators, B, 2011, 153, 340 .

36 S. Rajagopal, D. Nataraj, D. Mangalaraj, Y. Djaoued, J. Robichaud and O. Y. Khyzhun, Nanoscale Res. Lett., 2009, 4, 1335.

37 H. Y. Wong, C. W. Ong, R. W. M. Kwok, K. W. Wong, S. P. Wong and W. Y. Cheung, Thin Solid Films, 2000, 376, 131.

38 H.-S. Shim, J. W. Kim, Y.-E. Sung and W. B. Kim, Sol. Energy Mater. Sol. Cells, 2009, 93, 2062.

39 S. Pal and C. Jacob, Appl. Surf. Sci., 2007, 253, 3317.
40 F. Y. Xie, L. Gong, X. Liu, Y. T. Tao, W. H. Zhang, S. H. Chen, H. Meng and J. Chen, J. Electron Spectrosc. Relat. Phenom., 2012, 185, 112.

41 M. F. Daniel, B. Desbat, J. C. Lassegues, B. Gerand and M. Figlarz, J. Solid State Chem., 1987, 67, 235.

42 C. Santato, M. Odziemkowski, M. Ulmann and J. Augustynski, J. Am. Chem. Soc., 2001, 123, 10639.

43 T. Kubo and Y. Nishikitani, J. Electrochem. Soc., 1998, 145, 1729.

44 Y. Zou, P. W. May, S. M. C. Vieira and N. A. Fox, J. Appl. Phys., 2012, 112, 044903.

45 Y. B. Li, Y. Bando and D. Golberg, Adv. Mater., 2003, 15, 1294.

46 J. G. Liu, Z. J. Zhang, Y. Zhao, X. Su, S. Liu and E. G. Wang, Small, 2005, 1, 310.

47 F. Liu, T. Y. Guo, Z. Xu, H. B. Gan, L. F. Li, J. Chen, S. Z. Deng, N. S. Xu, D. Golberg and Y. Bando, J. Mater. Chem. C, 2013, 1, 3217, and references therein.

48 R. H. Fowler and L. W. Nordheim, Proc. R. Soc. London, Ser. A, 1928, 119, 173.

49 R. Seelaboyina, J. Huang, J. Park, D. H. Kang and W. B. Choi, Nanotechnology, 2005, 17, 4840. 